\title{
In Silico Study of Pyrazolylaminoquinazoline Toxicity by Lazar, Protox, and Admet Predictor
}

\author{
Supandi*, Yeni, Fajar Merdekawati \\ Department of Pharmacy, Faculty of Pharmacy and Sciences, UHAMKA, Jakarta, 13460, Indonesia.
}

\begin{tabular}{|c|c|}
\hline ARTICLE INFO & ABSTRACT \\
\hline $\begin{array}{l}\text { Article history: } \\
\text { Received on: } 29 / 03 / 2018 \\
\text { Accepted on: } 16 / 08 / 2018 \\
\text { Available online: } 30 / 09 / 2018\end{array}$ & $\begin{array}{l}\text { Pyrazolylaminoquinazoline is obtained from synthetic AZD4547 and can inhibit kinase activity in recombinant } \\
\text { fibroblast growth factor receptor (FGFR) in vitro. The objective of this study was to obtain high activity and low } \\
\text { toxicity pyrazolylaminoquinazoline derivatives in silico. The } 2 \text {-dimensional structures were generated using the } \\
\text { ChemDraw application. The Lazar application was used to predict endpoint carcinogenicity, maximum daily dose, } \\
\text { and mutagenicity. The ProTox application was used for endpoint LD50 and toxicity classes, while the ADMET }\end{array}$ \\
\hline $\begin{array}{l}\text { Key words: } \\
\text { In silico, } \\
\text { Pirazolilaminokuinazoline, } \\
\text { Lazar, ProTox, ADMET } \\
\text { Predictor }{ }^{\mathrm{TM}} \text {. }\end{array}$ & $\begin{array}{l}\text { application was used for endpoint hepatotoxicity, with reproductive system disorders, and endocrine. Based on the } \\
\text { scoring from the three software applications, two compounds were identified as being active against FGFR } 2 \text {, with no } \\
\text { carcinogenic or toxic effects on the liver, endocrine system, and the reproductive system, but they were predicted to } \\
\text { have mutagenic effects. These compounds were V29 (N-(5-(3,5-dimethoxy phenethyl - } 1 \mathrm{H} \text {-pyrazol-3-yl)-7(octahydro- } \\
2 \mathrm{H}-\text {-pyrido[1,2-a]pyrazine-2-yl) quinazoline-4-amine), with an IC50 of } 0.2 \pm 0.1 \mathrm{nM} \text { and a toxicity score of } 1027 \text {, and } \\
\text { V32 (N-(5-(3,5-dimethoxy phenethyl)-1H-pyrazol-3-yl)-7-(4-(dimethylamino)piperidine-1-yl)quinazoline-4-amine), } \\
\text { with an IC50 of } 0.3 \pm 0.1 \mathrm{nM} \text { and a toxicity score of } 1024 \text {. }\end{array}$ \\
\hline
\end{tabular}

\section{INTRODUCTION}

Many bioactive compounds have been shown to have anticancer activity, but their uses are limited due to side effects and high toxic effects (Malchers et al., 2017). Nonetheless, toxicity can be assessed using computational resources (computational algorithms, software, and data) to organize, analyze, model, simulate, visualize, or predict chemical toxicity (Raies and Bajic, 2016). Predicted toxicity in silico is performed prior to in vitro and in vivo testing to minimize the number of test compounds and test animals in subsequent tests. Such in silico tests include Lazy Structure-Activity Relationships (Lazar), Prediction of Rodent Oral Toxicity (ProTox), and ADMET Predictor ${ }^{\mathrm{TM}}$.

Lazar is a useful tool to predict the toxic properties of chemical structures. It produces predictions for the query structure of the database with experimentally determined toxicity data in the quantitative QSAR (quantitative structure-activity relationship) statistical approach. The performance of the Lazar software model

\section{"Corresponding Author}

Supandi, Department of Pharmacy, Faculty of Pharmacy and Sciences, UHAMKA, Jakarta, 13460, Indonesia.E-mail: supandi@uhamka.ac.id in the external validation dataset has an accuracy of $86 \%$ and a sensitivity of $78 \%$ in the carcinogenicity test, with $95 \%$ accuracy for the mutagenicity test (Helma, 2006).

ProTox is a web server for predicting small molecule oral toxicity in rodents. $\mathrm{LD}_{50}$ and toxicity classes are calculated on the basis of chemical compounds similar to those of toxic compounds. Researchers rely on known toxicity data to develop models that can predict the toxicity of new compounds. This web server calculates sensitivity, specificity, and precision for all considered toxicity classes, with values of $76 \%, 95 \%$, and $75 \%$ (Drwal et al., 2014).

ADMET Predictor ${ }^{\mathrm{TM}}$ uses integrated sequences to examine how the molecular structure of a compound plays a role in absorption, distribution, metabolism, excretion, and toxicology. The classification accuracy qualitatively reaches $85-90 \%$. The program has an intuitive user interface that allows visualization of the data (Hassan et al., 2013).

Pyrazolylaminoquinazoline derivative compounds can inhibit the fibroblast growth factor receptor (FGFR). Indeed, pyrazolilaminoquinazoline derivatives synthesized from AZD4547 have been shown to be effective, via targeting 
FGFR, against leukaemia in the KG-1 cell line (Gu et al., 2006), gastric cancer in the KATO III cell line (Kunii et al., 2008), bladder cancer in the RT112 cell line (Wang et al., 2014), and lung cancer in the H1581 cell line (Malchers et al., 2017). The $\mathrm{IC}_{50}$ values ranged from $0.2-10 \mathrm{Nm}$, but their toxicity was not determined. Therefore, this study aimed to predict the toxicity of pyrazolylaminoquinazoline derivatives in silico using Lazar, ProTox and ADMET PredictorTM applications. The results will help in the selection of anticancer drugs with high activity, but low toxicity prior to in vivo toxicity through preclinical testing. This is particularly important as in vivo animal testing is limited by time, ethical considerations, and a financial burden.

\section{MATERIALS AND METHODS}

\section{Equipment and materials}

The hardware used in this study was a PC with AMD A8-7410 Quad Core 2.2-2.5 GHz specification, with 4 gigabytes of DDR3 RAM and a Windows 10 Pro 64-bit operating system. The software used were ChemDraw Pro 16.0 (http://scistore. cambridgesoft.com/) under license code: 338-428260-4806, pkCSM (http://biosig.unimelb.edu.au/pkcsm/), Open Babel GUI
(http://openbabel.org/wiki/Category:Installation), Lazar (https:// lazar.in-silico.ch/predict), ProTox (http://tox.charite.de/tox/), and ADMET Predictor ${ }^{\mathrm{TM}}$ v8.0.4.62016 (http://simplusdownloads.com/ LicensingInstructions/AP8.html) with activation ID: 537-778-0308-2017-10-03-11-5095, Node Locked ID: CF9B5E81DD7C, and License Model: FIXED. The pyrazolylaminoquinazoline derivatives analyzed with $\mathrm{IC}_{50}$ values according to Fan et al., (2016) are shown in Table 1.

\section{Experimental procedure}

The 2D structure of 37 pyrazolylaminoquinazoline compounds was generated using the ChemDraw 2016 application. All pyrazolylaminoquinazoline compounds were screened using the pkCSM application to determine whether the compounds met Lipinski's Rule of Five. Compounds which did not meet the maximum two endpoints of Lipinski's Rule of Five were eliminated. The toxicity of the screened pyrazolylaminoquinozoline compounds was then predicted using Lazar for the carcinogenic endpoint, maximum daily dose, and mutagenicity, the ProTox application for $\mathrm{LD}_{50}$ endpoint and toxicity classes, as well as the ADMET Predictor application for hepatotoxicity endpoint, as well as reproductive system disorders, and endocrine.

Table 1: Pyrazolylaminoquinazoline derivatives.

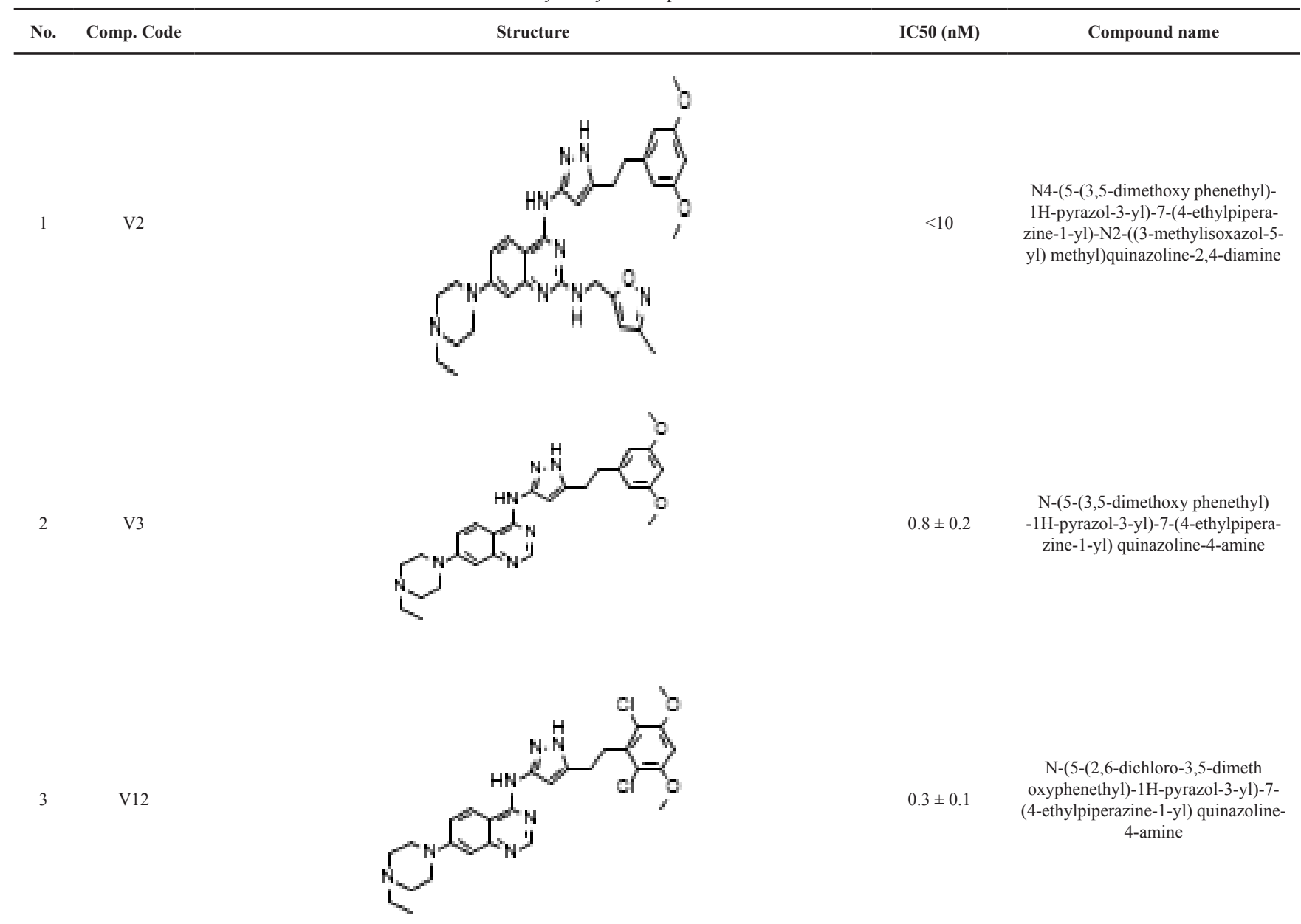




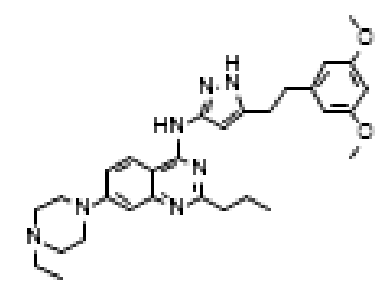<smiles>COc1cc(CCc2cc(Nc3ncnc4ccccc34)n[nH]2)cc(OC)c1</smiles>

N-(5-(3,5-dimethoxy phenethyl) -1H-pyrazol-3-yl)-7-(4-ethylpiperazine-1-yl) quinoline-4-amine

N-(5-(3,5-dimethoxy phenethyl) -1H-pyrazol-3-yl)-7-(4-ethylpiperazine-1-yl)-2-methylquinazoline-4amine

$\mathrm{N}-(5$-(3,5-dimethoxy phenethyl) -1H-pyrazol-3-yl)-2-ethyl-7-(4ethylpiperazine-1-yl) quinazoline-

$0.5 \pm 0.1$ 4-amine

$\mathrm{N}-(5-(3,5-$ dimethoxy phenethyl) -1H-pyrazol-3-yl)-7-(4-ethyl piper-

-1H-pyrazol-3-yl)-7-(4-ethyl piper-
azine-1-yl)-2-propyl quinazoline-
4-amine

$\mathrm{N}-(5-(3,5-$ dimethoxy phenethyl)- $1 \mathrm{H}-$
pyrazol-3-yl) quinazoline-4-amine

5-chloro-N-(5-(3,5-dimethoxy $16.9 \pm 0.2 \quad$ phenethyl)-1H-pyrazol-3-yl) quinazoline-4-amine 

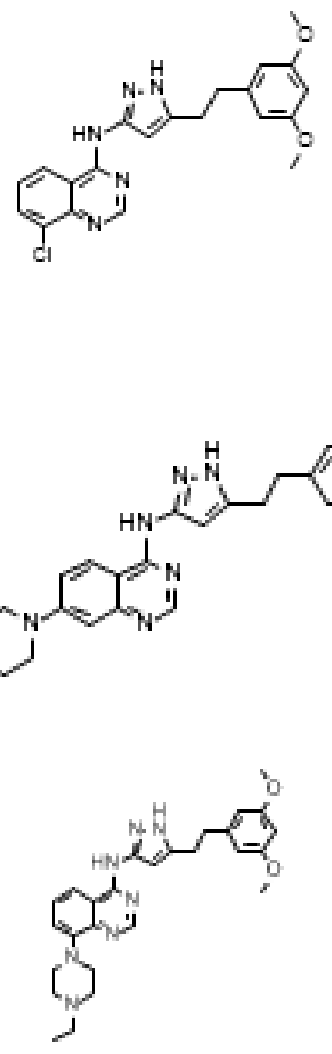

$100.9 \pm 0.2$

N-(5-(3,5-dimethoxy phenethyl) -1H-pyrazol-3-yl)-5-methoxyquinazoline-4-amine

8-chloro-N-(5-(3,5-dimethoxy $4.8 \pm 0.9 \quad$ phenethyl)-1H-pyrazol-3-yl) quinazoline-4-amine

N-(5-(3,5-dimethoxy phenethyl)

$3.9 \pm 0.1 \quad$ quinazoline- 4 -amine
qurazol-3-yl)-8-methoxy-

N-(5-(3,5-dimethoxy phenethyl) -1H-pyrazol-3-yl)-8-(4-ethylpiperazine-1-yl) quinazoline-4-amine

N-(5-(3,5-dimethoxy phenethyl) -1H-pyrazol-3-yl)-7-(4-methylpiperazine-1-yl)quinazoline-4-amine

$0.6 \pm 0.0$

$\mathrm{N}-(5-(3,5-$ dimethoxy phenethyl)-1Hpyrazol-3-yl)-7-(4-iso propylpiperazine-1-yl) quinazoline-4-amine 


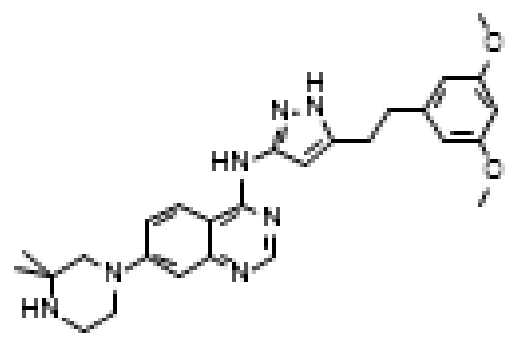

20

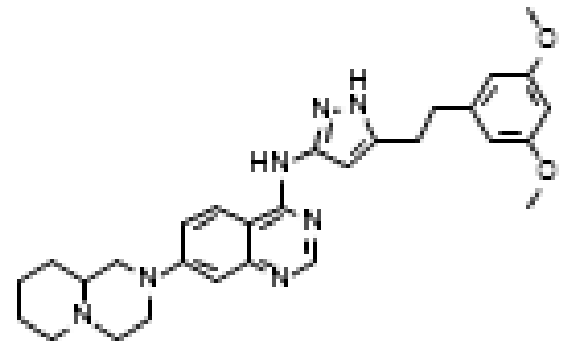

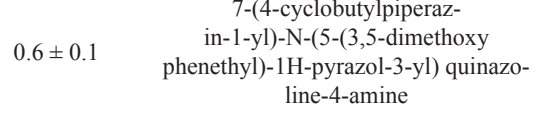

$0.7 \pm 0.2$

$\mathrm{N}-(5-(3,5-$ dimethoxy phenethyl)-1Hpyrazol-3-yl)-7-(4-(2-methoxyethyl) piperazine-1-yl)-2-quinazoline-4amine
$4.18 \pm 0.1$

$0.9 \pm 0.1$

$0.2 \pm 0.1$

$0.2 \pm 0.1$
$\mathrm{N}$-(5-(3,5-dimethoxy phenethyl)-1Hpyrazol-3-yl)-7-(4-tosylpiperazine-1 yl) quinazoline-4-amine
N-(5-(3,5-dimethoxy phenethyl) -1H-pyrazol-3-yl)-7-(3,3-di methylpiperazine-1-yl) quinazoline4-amine

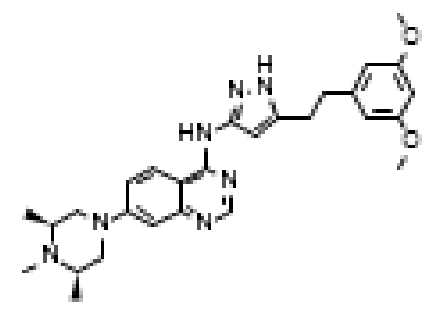

N-(5-(3,5-dimethoxy phenethyl)1H-pyrazol-3-yl)-7-((3S,5R)-3,4,5trimethyl piperazine-1-yl) quinazoline-4-amine 

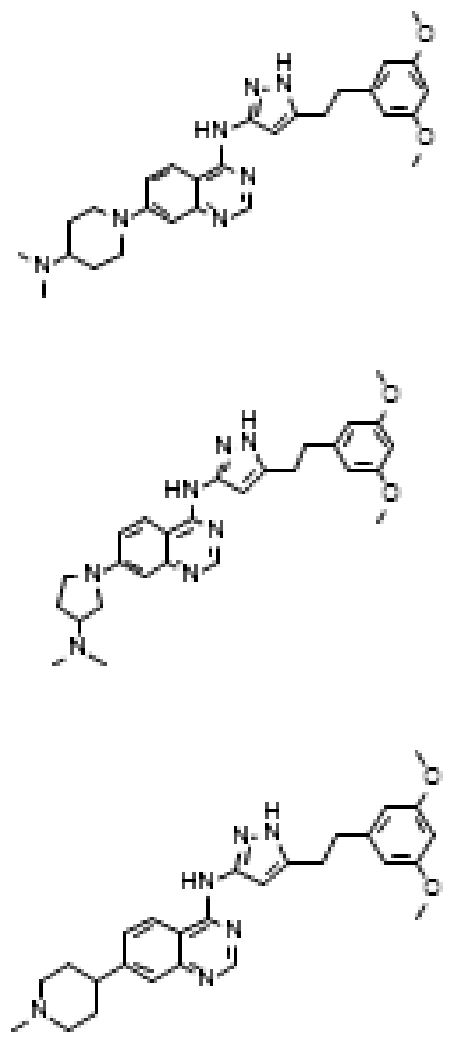

$0.7 \pm 0.2$

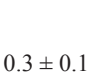

$0.3 \pm 0.1$

$0.4 \pm 0.2$

$0.4 \pm 0.2$

$0.8 \pm 0.1$

$0.8 \pm 0$.

N-(5-(3,5-dimethoxy phenethyl) -1H-pyrazol-3-yl)-7-(1-methylpiperidin-4-yl) quinazoline-4-amine
N-(5-(3,5-dimethoxy phenethyl) -1H-pyrazol-3-yl)-7-(4-(dimethylamino) piperidin -1-yl) quinazoline4-amine
$\mathrm{N}-(5-$-3,5-dimethoxy phenethyl)-1H-pyrazol-3-yl)-7-(3-(dimethylamino) pyrrolidin-1-yl)quinazoline-
$\mathrm{N}-(5-(3,5-$ dimethoxy phenethyl)-1Hpan-1-yl)quinazoline-4-amine 


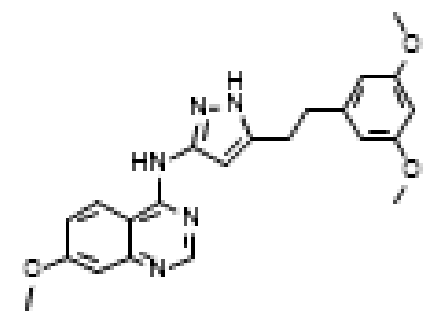<smiles>COCCOc1ccc2ncnc(Nc3cc(CCc4cc(OC)cc(OC)c4)[nH]n3)c2c1</smiles>

N4-(5-(3,5-dimethoxy pheneth$1.3 \pm 0.3 \quad$ yl)-1H-pyrazol-3-yl)-N7-(2-morpholinoethyl) quinazoline-4,7-diamine

$2.7 \pm 0.2$

N4-(5-(3,5-dimethoxy phenethyl)1H-pyrazol-3-yl)-N7-(2-methoxyethyl) quinazoline-4,7-diamine

N-(5-(3,5-dimethoxy phenethyl) $0.9 \pm 0.2 \quad-1$ H-pyrazol-3-yl)-7-(2-methoxyethoxy) quinazoline-4-amine

$\mathrm{N}-(5-(3,5-$ dimethoxy phenethyl) -1H-pyrazol-3-yl)-7-methoxyquinazoline-4-amine

$\mathrm{N}-(5-(3,5-$ dimethoxy phenethyl) -1H-pyrazol-3-yl)-6-(2-methoxye-1H-pyrazol-3-yl)-6-(4-ethylpiperazin-1-yl) quinazoline-4-amine 
V43

35

V44

36

V46
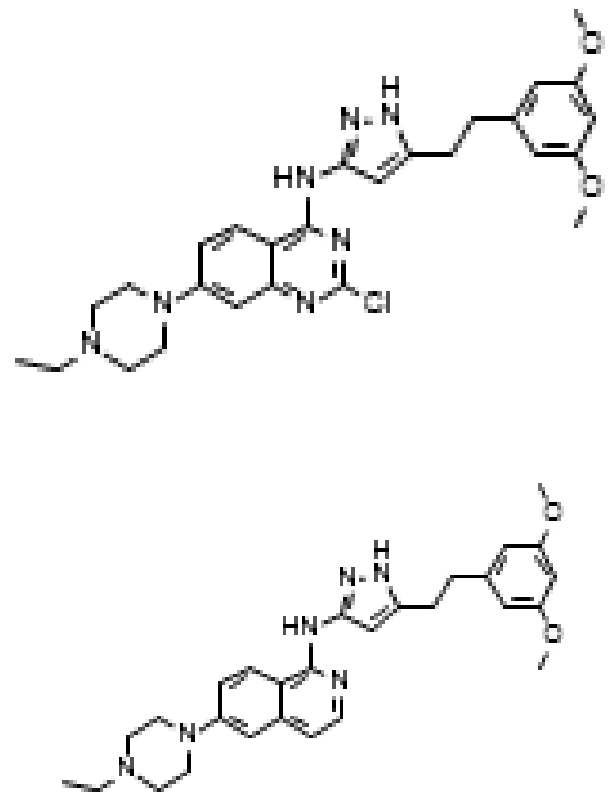
pyrazol-3-yl)-7-(4-ethylpiperazin-1yl)-6-methoxy quinazoline-4-amine

2-chloro-N-(5-(3,5-dimethoxy phenethyl)-1H-pyrazol-3-yl)-7-(4ethylpiperazine-1-yl) quinazoline4-amine

\section{Data analysis}

The predictions were in the form of quantitative and qualitative data. Qualitative data were expressed in positive and negative statements, then expressed in the form of scoring, where a positive toxic score is 1 and a negative toxic score is 2 . The data were scaled by summing all endpoints of the Lazar, ProTox, and ADMET predictions to obtain five compounds with the lowest toxicity, that is, the largest score. Five pyrazolylaminoquinazolin compounds were then selected which possessed high activity based on the in vitro test of Fan et al. (2016). The best compound was then obtained through the selected scoring model by comparing each compound with a low toxic effect, followed by the highest number of toxic negative endpoints. The next step selected two compounds with the highest activity and the lowest toxicity, by comparing the highest scores and the smallest $\mathrm{IC}_{50}$ value among the five compounds.

\section{RESULTS AND DISCUSSION}

\section{Lipinski's Rule of Five}

Lipinski's Rule of Five helps to determine the level of absorption or permeability of lipid bilayers present in the human body, demonstrating the oral bioavailability of a compound. Good bioavailability will satisfy the Lipinski rule, where the maximum molecular weight of the compound is 500 , the $\log \mathrm{P}$ is not more than 5 , the donor hydrogen bond is not more than 5 , and the number of hydrogen bond acceptor is less than 10 (Lipinski et al., 2001). The results of the Lipinski's Rule of Five calculations using pkCSM are presented in Table 2.

According to Table 2, all pyrazolylaminoquinazoline compounds met the Lipinski rule, so it can be predicted that all compounds have good absorptivity for oral medication. Veber et al. (2002) concluded that the lower molecular weight, log P, 
hydrogen bond donors, and hydrogen bond acceptor, the higher the bioavailability of a candidate drug.

\section{Toxicity prediction}

Based on the results of Lazar, carcinogenicity test prediction of Carcinogenic Potency Database (CPDB) with Leave One Out (LOO) cross-validation of the compounds V14, V15, V18, V21, V25-V26, V29, V31, V34, V39-V43, and V46 is non-carcinogenic, but V40 has the highest non-carcinogenic probability, with probability values 0.0895 for hamster, 0.102 for house mouse and 0.108 for mouse. The higher the non-carcinogen probability value, the higher the non-carcinogenic nature of a compound (Helma, 2006). Ranked from the highest to the lowest non-carcinogen probability values, the compounds are V40, V46,
V41, V21, V31, V39, V42, V29, V14, V15, V43, V26, V18, V34, and V25, while compounds V30, V32, V35, and V36 are carcinogens. Regarding the maximum daily dose prediction, the smaller the maximum dose, the more toxic the compound. The maximum daily dose could not be predicted for most compounds due to the lack of similar structures, except for compound $\mathrm{V} 13$, which was $7.57 \mathrm{mg} / \mathrm{kg} \mathrm{BW} /$ day. According to the in vitro mutagenicity prediction (Ames test) from the Kazius/Bursi dataset using LOO cross-validation in the CPDB application domain, 35 compounds were predicted to have a risk of a mutagen. However, compound V29 had the lowest mutagen probability with a value of 0.0988 . The lower the probability value of mutagen, the lower the mutagen property of a compound (Helma, 2006).

Table 2: Lipinski's Rule of Five Analysis Results.

\begin{tabular}{|c|c|c|c|c|c|c|c|c|c|}
\hline $\begin{array}{l}\text { Comp. } \\
\text { code }\end{array}$ & BM $(<500)$ & $\log P(<5)$ & Hydrogen Bond Acceptor & Hydrogen Bond Donor & $\begin{array}{l}\text { Comp. } \\
\text { code }\end{array}$ & BM $(<500)$ & $\log P(<5)$ & $\begin{array}{c}\text { Hydrogen } \\
\text { Bond Acceptor }\end{array}$ & $\begin{array}{l}\text { Hydrogen Bond } \\
\text { Donor }\end{array}$ \\
\hline V2 & 597.724 & 4.949 & 11 & 3 & V29 & 513.646 & 4.573 & 8 & 2 \\
\hline V3 & 487.608 & 4.041 & 8 & 2 & V30 & 501.635 & 4.428 & 8 & 2 \\
\hline V12 & 556.498 & 5.348 & 8 & 2 & V31 & 487.608 & 4.041 & 8 & 2 \\
\hline V13 & 486.62 & 4.646 & 7 & 2 & V32 & 501.635 & 4.429 & 8 & 2 \\
\hline V14 & 501.635 & 4.349 & 8 & 2 & V33 & 487.608 & 4.039 & 8 & 2 \\
\hline V15 & 515.662 & 4.603 & 8 & 2 & V34 & 472.593 & 4.708 & 7 & 2 \\
\hline V16 & 529.689 & 4.993 & 8 & 2 & V35 & 458.566 & 4.889 & 7 & 2 \\
\hline V17 & 375.432 & 3.899 & 6 & 2 & V36 & 460.538 & 3.736 & 8 & 2 \\
\hline V18 & 409.877 & 4.552 & 6 & 2 & V37 & 503.607 & 3.643 & 9 & 3 \\
\hline V19 & 405.458 & 3.908 & 7 & 2 & V38 & 448.527 & 3.957 & 8 & 3 \\
\hline V20 & 409.877 & 4.552 & 6 & 2 & V39 & 449.511 & 3.924 & 8 & 2 \\
\hline V21 & 405.458 & 3.908 & 7 & 2 & V40 & 405.458 & 3.908 & 7 & 2 \\
\hline V22 & 487.608 & 4.041 & 8 & 2 & V41 & 449.511 & 3.924 & 8 & 2 \\
\hline V23 & 473.581 & 3.651 & 8 & 2 & V42 & 487.608 & 4.041 & 8 & 2 \\
\hline V24 & 501.635 & 4.429 & 8 & 2 & V43 & 479.537 & 3.933 & 9 & 2 \\
\hline V25 & 513.646 & 4.573 & 8 & 2 & V44 & 517.634 & 4.049 & 9 & 2 \\
\hline V26 & 517.634 & 3.667 & 9 & 2 & V46 & 522.053 & 4.694 & 8 & 2 \\
\hline V27 & 613.744 & 4.718 & 9 & 2 & V50 & 486.62 & 4.646 & 7 & 2 \\
\hline V28 & 487.608 & 4.087 & 8 & 3 & & & & & \\
\hline
\end{tabular}

Regarding acute oral toxicity, based on the ProTox results, V37 compound was of moderate toxicity (Hodge and Sterner, 2005), with a $\mathrm{LD}_{50}$ value of $300 \mathrm{mg} / \mathrm{kgBB}$ and in class III Global Harmoni System (GHS) indicating that it could be toxic if swallowed (Drwal et al., 2014). Compound V34 had an $\mathrm{LD}_{50}$ value of $3,550 \mathrm{mg} / \mathrm{kgBW}$ and in class V GHS, so harmful if swallowed (Drwal et al., 2014). It belongs to class IV (500$5.000 \mathrm{mg} / \mathrm{kgBB}$ ) according to Hodge and Sterner (2005), so it is mildly toxic. The thirty-three other compounds had $\mathrm{LD}_{50}$ values between $380-1130 \mathrm{mg} / \mathrm{kgBW}$ and were class IV GHS IV toxicity class, indicating that they are dangerous if swallowed (Drwal et al., 2014). Furthermore, they were also class III (50-500 mg/ $\mathrm{kgBW})$ to grade IV (500-5000 mg/kgBW), which means they had moderate to mild toxicity (Hodge and Sterner, 2005).

Based on the results of ADMET Predictor, hepatotoxicity test, endocrine system toxicity, and repro toxicity, it can be seen that compounds V3, V14, V15, V23-V33, V35, V36, and V46 are predicted to have no toxic risk to liver function, the endocrine system, and the reproduction system. Hepatotoxicity predicts five increased serum enzymes for the diagnosis of liver damage, namely alkaline phosphatase (ALP), gamma glutamyl transferase (GGT), lactate dehydrogenase (LDH), aspartate transaminase/ serum glutamate oxaloacetate transferase (AST/SGOT), and alanine transaminase/serum glutamate pyruvate transferase (ALT/ SGPT). Hepatotoxicity prediction is issued by the Food and Drug Administration (FDA) on the side effects for human liver, based on two databases, the Spontaneous Reporting System (SRS) and the Adverse Event Reporting System (AERS). SRS data distinguishes three classes of compounds: inactive $(\mathrm{RI}<3.0)$, slightly active $(3.0 \leq \mathrm{RI}<4.0)$, and active $(\mathrm{RI} \geq 4.0)$. The ADMET Predictor sets the RI cut-off value at 3.0, therefore, the molecule with an $\mathrm{RI}<3.0$ is categorized as negative (normal) and with $\mathrm{RI} \geq 3.0$ as positive (not normal) in each enzyme (Hassan et al., 2013; Simulations Plus, 2016). 
Table 3: Toxicity prediction results from Lazar, ProTox, and ADMET predictor.

\begin{tabular}{|c|c|c|c|c|c|c|c|c|c|c|c|c|c|c|c|c|c|}
\hline Comp. Code & $\mathbf{A}$ & B & C & D & $\mathbf{E}$ & $\mathbf{F}$ & G & $\mathbf{H}$ & I & $\mathbf{J}$ & $\mathbf{K}$ & $\mathbf{L}$ & $\mathbf{M}$ & $\mathbf{N}$ & o & Total & Average \\
\hline V12 & 1 & 2 & 2 & 0 & 1 & 500 & 4 & 2 & 2 & 2 & 2 & 2 & 2 & 2 & 2 & 526 & 35.06 \\
\hline V13 & 1 & 2 & 2 & 7.57 & 1 & 500 & 4 & 2 & 2 & 1 & 2 & 2 & 1 & 2 & 2 & 531 & 35.43 \\
\hline V14 & 2 & 2 & 2 & 0 & 1 & 1000 & 4 & 2 & 2 & 2 & 2 & 2 & 2 & 2 & 2 & 1027 & 68.46 \\
\hline V15 & 2 & 2 & 2 & 0 & 1 & 1000 & 4 & 2 & 2 & 2 & 2 & 2 & 2 & 2 & 2 & 1027 & 68.46 \\
\hline V16 & 1 & 2 & 2 & 0 & 1 & 1000 & 4 & 2 & 2 & 2 & 2 & 2 & 2 & 1 & 2 & 1025 & 68.33 \\
\hline V17 & 1 & 1 & 2 & 0 & 1 & 1060 & 4 & 2 & 1 & 1 & 2 & 2 & 2 & 2 & 2 & 1083 & 72.20 \\
\hline V18 & 2 & 2 & 2 & 0 & 1 & 1000 & 4 & 2 & 1 & 1 & 2 & 2 & 2 & 2 & 2 & 1025 & 68.33 \\
\hline V19 & 1 & 1 & 2 & 0 & 1 & 1130 & 4 & 2 & 1 & 1 & 2 & 2 & 2 & 2 & 2 & 1153 & 76.87 \\
\hline V20 & 1 & 1 & 2 & 0 & 1 & 1130 & 4 & 2 & 1 & 1 & 2 & 2 & 2 & 2 & 2 & 1153 & 76.86 \\
\hline $\mathrm{V} 21$ & 2 & 2 & 2 & 0 & 1 & 1000 & 4 & 2 & 1 & 1 & 2 & 2 & 2 & 2 & 2 & 1025 & 68.33 \\
\hline V22 & 1 & 1 & 2 & 0 & 1 & 625 & 4 & 2 & 2 & 1 & 2 & 2 & 2 & 2 & 2 & 649 & 43.26 \\
\hline V23 & 1 & 1 & 2 & 0 & 1 & 500 & 4 & 2 & 2 & 2 & 2 & 2 & 2 & 2 & 2 & 525 & 35.00 \\
\hline V24 & 1 & 1 & 2 & 0 & 1 & 500 & 4 & 2 & 2 & 2 & 2 & 2 & 2 & 2 & 2 & 525 & 35.00 \\
\hline V25 & 2 & 2 & 2 & 0 & 1 & 500 & 4 & 2 & 2 & 2 & 2 & 2 & 2 & 2 & 2 & 527 & 35.13 \\
\hline V26 & 2 & 2 & 2 & 0 & 1 & 380 & 4 & 2 & 2 & 2 & 2 & 2 & 2 & 2 & 2 & 407 & 27.13 \\
\hline V27 & 1 & 1 & 2 & 0 & 1 & 1000 & 4 & 2 & 2 & 2 & 2 & 2 & 2 & 2 & 2 & 1025 & 68.33 \\
\hline V28 & 1 & 1 & 2 & 0 & 1 & 500 & 4 & 2 & 2 & 2 & 2 & 2 & 2 & 2 & 2 & 525 & 35.00 \\
\hline V29 & 2 & 2 & 2 & 0 & 1 & 1000 & 4 & 2 & 2 & 2 & 2 & 2 & 2 & 2 & 2 & 1027 & 68.46 \\
\hline V30 & 1 & 1 & 1 & 0 & 1 & 500 & 4 & 2 & 2 & 2 & 2 & 2 & 2 & 2 & 2 & 524 & 34.93 \\
\hline V31 & 2 & 2 & 2 & 0 & 1 & 500 & 4 & 2 & 2 & 2 & 2 & 2 & 2 & 2 & 2 & 527 & 35.13 \\
\hline V32 & 1 & 1 & 1 & 0 & 1 & 1000 & 4 & 2 & 2 & 2 & 2 & 2 & 2 & 2 & 2 & 1024 & 68.26 \\
\hline V33 & 1 & 1 & 2 & 0 & 1 & 500 & 4 & 2 & 2 & 2 & 2 & 2 & 2 & 2 & 2 & 525 & 35.00 \\
\hline V34 & 2 & 2 & 2 & 0 & 1 & 3550 & 5 & 2 & 2 & 1 & 2 & 2 & 2 & 2 & 2 & 3577 & 238.46 \\
\hline V35 & 1 & 1 & 1 & 0 & 1 & 1000 & 4 & 2 & 2 & 2 & 2 & 2 & 2 & 2 & 2 & 1024 & 68.26 \\
\hline V36 & 1 & 1 & 1 & 0 & 1 & 500 & 4 & 2 & 2 & 2 & 2 & 2 & 2 & 2 & 2 & 524 & 34.933 \\
\hline V37 & 1 & 2 & 2 & 0 & 1 & 300 & 3 & 2 & 2 & 1 & 2 & 2 & 2 & 2 & 2 & 324 & 21.60 \\
\hline V38 & 1 & 1 & 2 & 0 & 1 & 500 & 4 & 2 & 2 & 1 & 2 & 2 & 2 & 2 & 2 & 524 & 34.93 \\
\hline V39 & 2 & 2 & 2 & 0 & 1 & 1060 & 4 & 2 & 2 & 1 & 2 & 2 & 2 & 2 & 2 & 1086 & 72.40 \\
\hline V40 & 2 & 2 & 2 & 0 & 1 & 1130 & 4 & 2 & 1 & 1 & 2 & 2 & 2 & 2 & 2 & 1155 & 77.00 \\
\hline V41 & 2 & 2 & 2 & 0 & 1 & 1060 & 4 & 2 & 2 & 1 & 2 & 2 & 2 & 2 & 2 & 1086 & 72.40 \\
\hline V42 & 2 & 2 & 2 & 0 & 1 & 500 & 4 & 2 & 2 & 1 & 2 & 2 & 2 & 2 & 2 & 526 & 35.06 \\
\hline V43 & 2 & 2 & 2 & 0 & 1 & 1060 & 4 & 2 & 2 & 1 & 2 & 2 & 2 & 2 & 2 & 1086 & 72.40 \\
\hline V44 & 1 & 1 & 2 & 0 & 1 & 500 & 4 & 2 & 2 & 1 & 2 & 2 & 2 & 2 & 2 & 524 & 34.93 \\
\hline V46 & 2 & 2 & 2 & 0 & 1 & 500 & 4 & 2 & 2 & 2 & 2 & 2 & 2 & 2 & 2 & 527 & 35.13 \\
\hline V50 & 1 & 1 & 2 & 0 & 1 & 740 & 4 & 2 & 2 & 1 & 2 & 2 & 2 & 2 & 2 & 764 & 50.93 \\
\hline
\end{tabular}

where A: Hamster Carcinogenicity Test, B: House mouse Carcinogenicity Test, C: Mouse Carcinogenicity Test, D: Maximal Daily Dosage, E: Mutagenicity Test, F: LD $_{50}$, G: Toxicity Class (Class 1-6), H: ALP Test, I: GGT Test, J: LDH Test, K: AST Test, L: ALT Test, M: Oestrogen Test, N: Androgen Test, O: Reprocytocity Test, 0: unknown, 1: Positive Toxicity, 2: Negative Toxicity.

Based on the results of the scoring calculations of the three software applications in Table 3, the compound with the lowest toxicity has the highest average scores, which is V34, predicted to cause toxicity to LDH enzymes and V19, V20, and V40 predicted to be toxic to GGT and LDH enzymes. V43 is less effective than the best compound due to its high $\mathrm{LD}_{50}$ value 
and predicted to be toxic to the liver. Therefore, further analysis is required by comparing the number of non-toxic endpoints for each compound.

From the analysis results, it is predicted that V14, V15, V25, V26, V29, V31 and V46 compounds have no carcinogenic, toxic effects on the liver, endocrine systems, and reproductive systems, but they are predicted to have mutagenic effects. The higher the $\mathrm{LD}_{50}$ of a compound, the lower the toxic effect. V14, $\mathrm{V} 15$, and V29 compounds have an $\mathrm{LD}_{50}$ of $1.000 \mathrm{mg} / \mathrm{kgBW}, \mathrm{V} 25$, $\mathrm{V} 31$, and V46 have an $\mathrm{LD}_{50}$ of $500 \mathrm{mg} / \mathrm{kgBW}$, while V26 has an $\mathrm{LD}_{50}$ of $380 \mathrm{mg} / \mathrm{kgBW}$, so V26 compound was not selected for the lowest toxic effect.

The lowest mutagen effect has the smallest mutagenic probability value. V14, V15, V25, V29, V31 and V46 compounds have mutagenic probability values of $0.129,0.125,0.107,0.0988$, 0.159 and 0.127 respectively, so V31 was not selected for the lowest toxic effect. V14, V15, V25, V29, and V32 have the lowest toxicity with $\mathrm{IC}_{50}$ values of $0.6 \mathrm{nM}, 0.5 \mathrm{nM}, 0.6 \mathrm{nM}, 0.2 \mathrm{nM}$ and $0.3 \mathrm{nM}$ respectively.

\section{CONCLUSION}

The in silico applications, Lazar, ProTox, and ADMET, were used to predict the toxicity of anticancer pyrazolylaminoquinazolin compounds, revealing that the two compounds with the highest activity and the lowest toxicity were V29 (N-(5-(3,5-dimethoxy phenethyl)-1H-pyrazol-3-yl)7(octahydro-2H-pyrido [1,2-a] pyrazine-2-yl) quinazoline-4amine), with a IC50 of $0.2 \pm 0.1 \mathrm{nM}$ and a toxicity score of 1027 , and V32 (N-(5-(3,5-dimethoxy phenethyl)-1H-pyrazol-3-yl)-7(4-(dimethylamino)piperidine-1-yl)quinazoline-4-amine) with an IC50 of $0.3 \pm 0.1 \mathrm{nM}$ and a toxicity score of 1024 .

\section{AUTHORS CONTRIBUTIONS}

All authors contributed equally.

\section{CONFLICTS OF INTERESTS}

All authors have none to declare.

\section{REFERENCES}

Malchers F, Ercanoglu M, Scutte D, Castiglione R, Tischler $\mathrm{V}$, Michels S, et al. Mechanisme of Primary Drug Resistance in FGFR1 Amplified Lung Cancer. Clin Cancer Res, 2017; 27(18):5527-5536.
Raies AB, Bajic VB. In silico toxicology: computational methods for the prediction of chemical toxicity. WIREs Comput Mol Sci, 2016; 6:147-172.

Helma C. Lazy Structure Activity Relationships (Lazar) for the Prediction of Rodent Carcinogenicity and Salmonella Mutagenicity. Mol Diversity, 2006; 10:147-158.

Drwal MN, Banerjee P, Dunkel M, Wettig MR, Preissner R. ProTox: a web server for the in silico prediction of rodent oral toxicity. Nucleic Acids Res, 2014; 10:1-6.

Hassan SF, Rashid U, Ansari FL, Ul-Haq Z. Bioisosteric Approach in Designing New Monastrol Derivatives: An Investigation on Their ADMET Prediction Using In Silico Derived Parameters. J Mol Graph Model, 2013; 45:202-210.

Gu T, Goss VL, Reeves C, Popova L, Nardone J, MacNeill J, et al. Phosphotyrosine profiling identifies the KG-1 cell line as a model for the study of FGFR1 fusions in acute myeloid leukemia. Blood, 2006; 108(13):4202-4204.

Kunii K, Davis L, Gorenstein J, Hatch J, Yashiro M, Bacca AD. FGFR-2 Amplified Gstric Cancer Cell Line Require FGFR2 and Erbb3 Signaling for Growth and Survival. Cancer Res, 2008; 68 (7):2340-2348.

Wang J, Mikse O, Liao RG, Li Y, Tan L, Janne PA, et al. Ligand Associated ERBB2/3 Actifation Confers Acquired Resistance to FGFR Inhibition in FGFR3 Dependent Cancer Cells. Oncogene, 2014; 10:1-11.

Fan J, Dai Y, Shao J, Peng X, Wang C, Cao S, Zhao B, Ai J, Geng M, Duan W. Design, Synthesis and Biological Evaluation of Pyrazolylaminoquinazoline Derivatives as Highly Potent pan-Fibroblast Growth Factor Reseptor Inhibitors. Bioorg Med Chem Let, 2016; 26(11):2594-2599.

Lipinski CA, Lombardo F, Domminy BW, Feeney PJ. Experimental and computational approaches to estimate solubility and permeability in drug discovery and development settings. Adv Drug Deliv Rev, 2001; 46:3-26.

Veber DV, Jhonson SR, Cheng HY, Smith BR, Ward KW, Kopple KB. Molecular Properties That Influence the Oral Bioavailability of Drug Candidates. J Med Chem, 2002; 45(12):2616-2623.

Hodge A, Sterner B. 2005. Toxicity Classes. In: Canadian Center for Occupational Health and Safety. [Cited 2017 August 4]. Available from: http://www.ccohs.ca/oshanswers/chemicals/id50.htm.

Simulations Plus. 2016. ADMET PredictorTM versi 8.0.4.6. Simulations Plus Inc. California. [Cited 2017 August 4]. Available from: http://www.simulations-plus.com/.

How to cite this article:

Supandi, Yeni, Merdekawati F. In Silico Study of Pyrazolylaminoquinazoline Toxicity by Lazar, Protox, and Admet Predictor. J App Pharm Sci, 2018; 8(09): 119-129. 